\title{
Analisis Multivariat Untuk Melihat Hubungan Jenis Sedimen Terhadap Jenis Lamun
}

\author{
Ardian Nurrasyid Chamidy*, Chrisna Adhi Suryono, Ita Riniatsih \\ Departemen IImu Kelautan, Fakultas Perikanan dan IImu Kelautan, Universitas Diponegoro \\ JI. Prof.H.Soedarto S.H, Tembalang, Semarang, Jawa Tengah 50275 Indonesia \\ ${ }^{*}$ Corresponding author, e-mail : ardianchamidy@gmail.com
}

\begin{abstract}
ABSTRAK: Perairan Teluk Awur dan Pulau Panjang memiliki kondisi perairan yang berbeda dan merupakan perairan yang masih baik untuk pertumbuhan lamun. Ekosistem padang lamun tumbuh pada sedimen dan hidup terendam di dalam air laut. Komposisi jenis sedimen diduga dapat menyebabkan perbedaan komposisi jenis lamun yang didasari oleh pemikiran bahwa perbedaan komposisi ukuran butir sedimen akan menyebabkan perbedaan nutrisi bagi pertumbuhan lamun. Penelitian ini bertujuan untuk mengkaji hubungan jenis sedimen terhadap jenis lamun di perairan Teluk Awur dan Pulau Panjang Jepara dengan menggunakan analisis multivariat. Penelitian ini dilakukan dalam beberapa tahap yang meliputi tahap persiapan, tahap penentuan stasiun dengan metode sampling purposive method, tahap pengambilan data lapangan, tahap analisis tekstur sedimen yang dilakukan di laboratorium teknik sipil fakultas teknik Universitas Diponegoro, dan tahap analisis data menggunakan analasis multivariat yaitu Principal Component Analysis (PCA). Hasil analisis PCA menunjukkan bahwa Cymodocea serrulata dan Cymodocea rotundata berkorelasi positif dengan sand, kecepatan arus, dan $\mathrm{pH}$. Thalassia hemprichii dan Enhalus acoroides memiliki korelasi positif dengan silt, clay, suhu, salinitas dan bahan organik. Grave/ memiliki korelasi postif dengan nitrat dan fosfat.
\end{abstract}

Kata kunci: Sedimen; Lamun; Analisis Multivariat; Teluk Awur; Pulau Panjang

\section{Multivariate Analysis To See The Relationship Of Sediment Types To Seagrass Species}

ABSTRACT: The waters of Teluk Awur and Panjang Island have different water conditions and are still good waters for seagrass growth. Seagrass ecosystems grow in sediments and live submerged in seawater. The composition of the substrate types is thought to cause differences in the composition of seagrass types based on the thought that differences in the composition of sediment grain size will cause differences in nutrition for seagrass growth. This study aims to examine the relationship of sediment types to seagrass species in Teluk Awur and Pulau Panjang, Jepara by using multivariate analysis. This research was conducted in several stages including the preparation stage, the stage of determining stations with the purposive sampling method, the stage of field data collection, the stage of sediment texture analysis carried out in the civil engineering laboratory of the engineering faculty Diponegoro University, and the stage of data analysis using multivariate analysis with Principal Component Analysis (PCA). PCA analysis results show that Cymodocea serrulata and Cymodocea rotundata are positively correlated with sand, current speed, and $\mathrm{pH}$. Thalassia hemprichii and Enhalus acoroides have a positive correlation with silt, clay, temperature, salinity and organic matter. Gravel has a positive correlation with nitrate and phosphate.

Keywords: Sediment; Seagrass; Multivariate Analysis; Teluk Awur; Panjang Island

\section{PENDAHULUAN}

Perairan Teluk Awur dan Pulau Panjang terletak di Kabupaten Jepara Jawa Tengah. Perairan tersebut memiliki kondisi perairan yang berbeda dan merupakan perairan yang masih baik untuk pertumbuhan lamun (Prasetya et al., 2015). Pulau Panjang merupakan daerah wisata dengan perairan terbuka sehingga sangat dipengaruhi oleh ombak dan gelombang. (Setyaboma et al., 2015). Teluk Awur merupakan perairan tertutup dengan kekuatan arus dan gelombang 
akan berkurang ketika sampai di pantai. Perairan Teluk Awur memiliki keanekaragaman jenis lamun yang relative tinggi, namun dengan berjalannya waktu dan banyaknya aktivitas manusia yang memanfaatkan lokasi tersebut berdampak pada kelestarian padang lamun di dalamnya (Riniatsih, 2016).

Tumbuhan lamun mampu hidup pada berbagai macam tipe substrat mulai dari lumpur hingga pecahan karang (Dahuri et al., 2001). Klasifikasi tipe substrat seperti berbatu, berpasir, pasir berlumpur, dan lumpur berpasir didasari oleh komposisi partikel yang terkandung dalam substrat (Feryatun et al., 2012). Karakteristik substrat berpengaruh terhadap struktur dan kelimpahan lamun (De Silva dan Amarasinghe, 2007). Komposisi jenis substrat juga memainkan peranan penting dalam sistem perakaran lamun. Lamun yang hidup di substrat rubble dan pasir cenderung memiliki perakaran yang lebih kuat dibandingkan lamun yang hidup di substrat berlumpur. Hal ini karena porositas pasir yang besar dan seragam sehingga akar perlu mencengkram kuat ke substrat agar dapat bertahan dari arus dan gelombang. Sedangkan lamun yang tumbuh pada substrat berlumpur memiliki ukuran butir sedimen yang halus, sehingga membutuhkan lebih banyak akar untuk mengikat sedimen.

Penelitian yang dilakukan Bengkal et al. (2019), di Kelurahan Tongkaina Manado, mendapatkan hasil yaitu jenis sedimen dengan komposisi dominan pasir dan lumpur terdaapat spesies lamun Enhalus acoroides, Thalassia hemprichii, Cymodocea serrulata, Cymodocea rotundata dan Syringodium isoetifolium, sedangkan jenis sedimen dengan komposisi dominan lumpur terdapat spesies lamun Enhalus acoroides dan Thalassia hemprichii. Penelitian yang dilakukan Adli et al. (2016), di perairan Sabang Tende Kabupaten Tolitoli mendapatkan hasil yaitu jenis sedimen pasir berlumpur terdepat spesies lamun Enhalus acoroides, Thalassia hemprichii dan Halophila ovalis. Jenis sedimen pasir berkarang terdapat spesies lamun Enhalus acoroides, Thalassia hemprichii, Halophila ovalis, Halodule pinifolia, Cymodocea rotundata dan Syringodium isoetifolium. Jenis sedimen berpasir terdapat spesies lamun Enhalus acoroides, Thalassia hemprichii, Halophila ovalis, Halodule pinifolia dan Cymodocea rotundata. Penelitian yang dilakukan Rustam et al. (2015), di Pulau Lembeh Belitung Sulawesi Selatan mendapatkan hasil yaitu Enhalus acoroides dapat tumbuh pada substrat lumpur berpasir, pasir dan pecahan karang. Thalassia hemprichii tumbuh pada sedimen pasir dan pecahan karang. Cymodocea rotundata dan Cymodocea serrulata tumbuh pada sedimen pasir. Untuk itu perlu dilakukan penelitian ini dengan tujuan untuk mengkaji hubungan jenis sedimen terhadap jenis lamun di perairan Teluk Awur dan Pulau Panjang Jepara dengan menggunakan analisis multivariat.

\section{MATERI DAN METODE}

Penelitian ini dilaksanakan pada bulan Juni 2019 di perairan Pulau Panjang dan Teluk Awur Jepara. Materi yang digunakan pada penelitian ini adalah sampel sedimen untuk analisa ukuran butir sebagai variabel bebas, lamun untuk Identifikasi jenis dan jumlah tegakan sebagai variabel terikat serta Parameter kualitas perairan seperti suhu, salinitas, $\mathrm{pH}$, kecepatan arus, kecerahan, nutrient sedimen dan fosfat sedimen sebagai variabel bebas pendukung lamun. Penentuan lokasi penelitian menggunakan teknik pengambilan purposive sampling yaitu penentuan lokasi sampling dengan beberapa pertimbangan tertentu oleh peneliti (Hartati et al., 2017). Lokasi pengambilan sampel terdiri atas dua stasiun setiap lokasinya. Masingmasing stasiun terdapat tiga titik pengambilan sampel yang ditentukan secara acak dengan jarak 50 meter setiap titiknya.

Pengambilan contoh sedimen dilakukan di dua stasiun dengan menggunakan Sediment core yang berukuran $30 \mathrm{~cm}$ dengan diameter $10 \mathrm{~cm}$. Sediment Core ditancapkan ke dalam substrat, kemudian ditekan sampai kedalaman $10 \mathrm{~cm}$ (Handoko et al., 2017). Sedimen yang telah diambil dimasukan kedalam ziplok. Pengamatan lamun di lapangan meliputi identifikasi jenis-jenis lamun dan menghitung jumlah individu / tegakan dihitung menggunakan kuadrat transek berukuran 50 $\mathrm{cm} \times 50 \mathrm{~cm}$ yang masing masing dibagi menjadi 4 sub petak, berukuran $25 \mathrm{~cm} \times 25 \mathrm{~cm}$ (Rahmawati et al., 2014). Transek diletakkan di daerah padang lamun pada lokasi yang telah ditentukan. Analisis sedimen berdasarkan ukuran butir dengan menggunakan metode pengayakan (sieve shaker) yang bertujuan untuk mengetahui komposisi ukuran butir 
sedimen dengan diameter diatas $0,074 \mathrm{~mm}$. Metode pengayakan dilakukan dengan cara membersihkan sampel dari kotoran dan lamun yang menempel pada sedimen, kemudian sampel dikering anginkan. Sampel sedimen ditimbang seberat 100 gram sebagai berat awal, kemudian diayak menggunakan sieve shaker yang tersusun secara berurutan dengan ukuran $4.76 \mathrm{~mm}$, $3.36 \mathrm{~mm}, 2 \mathrm{~mm}, 0.841 \mathrm{~mm}, 0.42 \mathrm{~mm}, 0.25 \mathrm{~mm}, 0.149$ dan <0.074 mm. Kemudian sampel sedimen dipisahkan dari ayakan lalu ditimbang (Saputra et al., 2013).

Data berupa jenis sedimen berdasarkan ukuran butir, jenis lamun, jumlah tegakan lamun dan parameter kualitas perairan dianalisa dengan pengujian statistik Pricipal Component Analysis menggunakan aplikasi XLSTAT 2015. PCA (Principal Component Analysis) adalah teknik statistik yang diaplikasikan untuk satu kumpulan variabel dalam menemukan variabel mana dalam kumpulan tersebut yang berhubungan dengan lainnya (Umar, 2009).

\section{HASIL DAN PEMBAHASAN}

Hasil penelitian yang dilakukan menunjukkan bahwa fraksi sedimen sand lebih dominan ditemukan di Teluk Awur dan Pulau Panjang, sehingga klasifikasi substrat yang terdapat dikedua lokasi tersebut yaitu gravely sand, sand dan muddy sand. Hasil tersebut diperkuat oleh penelitian Hidayat et al. (2014), substrat yang ditemukan di Pulau Panjang yaitu sand dan muddy sand. Menurut Safwan et al. (2016), Substrat yang terdapat di Teluk Awur yaitu sand, gravely sand dan muddy sand. Kesesuaian substrat merupakan faktor penting bagi perkembangan lamun. Lamun biasanya tumbuh pada daerah pasang surut terbuka serta perairan pantai yang substratnya berupa pasir, pasir berlumpur, lumpur berpasir, lumpur lunak dan pecahan karang (Azkab, 2006). Sehingga kedua lokasi tersebut dapat ditumbuhi lamun. Jenis lamun yang ditemukan di Teluk Awur yaitu Thalassia hemprichii dan Enhalus acoroides sedangkan jenis lamun yang ditemukan di Pulau Panjang yaitu Enhalus acoroides, Thalassia hemprichii, Cymodocea serrulata dan Cymodocea rotundata. Hal tersebut sesuai dengan penelitian yang dilakukan oleh Riniatsih (2016), Jenis lamun Thalassia hemprichii dan Enhalus acoroides ditemukan di perairan Teluk Awur. Setiawati (2013), jenis lamun Enhalus acoroides, Thalassia hemprichii, Cymodocea rotundata dan Cymodocea serrulata. ditemukan di perairan Pulau Panjang Jepara. Jenis lamun yang ditemukan, memiliki komposisi jumlah tegakan yang berbeda pada setiap stasiun. Hasil analisis statistik dengan Principal Component Analysis menunjukkan korelasi antar variabel, hal ini menunjukkan bahwa Cymodocea serrulata dan Cymodocea rotundata berkorelasi positif dengan sand, arus dan $\mathrm{pH}$. Thalassia hemprichii dan Enhalus acoroides memiliki korelasi positif dengan silt, clay, suhu, salinitas dan bahan organik. Gravel memiliki korelasi postif dengan nitrat dan fosfat (Gambar 1).

Analisis PCA (Gambar 1) menunjukkan bahwa jenis lamun Cymodocea rotundata dan Cymodocea serrulata lebih dominan ditemukan pada stasiun 2 Pulau Panjang dengan jenis sedimen pasir yang memiliki nilai sedimen pasir lebih tinggi dibandingkan stasiun lainnya dengan kecepatan arus yang tinggi dan $\mathrm{pH}$ normal, hal tersebut diperkuat oleh Nabilla et al. (2019) kepadatan lamun Cymodocea serrulata tinggi bersubstrat pasir yang diduga jenis substrat pasir merupakan daerah yang disukai lamun jenis tersebut untuk hidup. Cymodocea rotundata tumbuh pada substrat pasir dan pecahan karang, terbuka saat surut dan selalu digenangi air juga merupakan salah satu lamun jenis yang dominan di daerah intertidal Hutomo et al. (1988) dalam Ganefiani et al. (2019). Jenis lamun Thalassia hemprichii dan Enhalus acoroides lebih dominan ditemukan pada stasiun 2 Teluk Awur dan stasiun 1 Pulau Panjang dengan jenis sedimen pasir berlumpur yang memiliki nilai silt dan clay lebih tinggi dibandingkan stasiun lainnya dengan nilai suhu, salinitas, dan bahan organik yang tinggi. Menurut Short dan Coles (2001) dalam Hartati et al. (2017), spesies Enhalus acoroides umumnya ditemukan tumbuh pada substrat berlumpur di perairan yang keruh, dapat membentuk spesies tunggal serta dapat mendominasi komunitas padang lamun. Menurut Riniatsih (2016), Thalassia hemprichii dan Enhalus acoroides cenderung menyebar pada habitat dengan substrat pasir berlumpur dengan kandungan bahan organik yang relatif tinggi. 


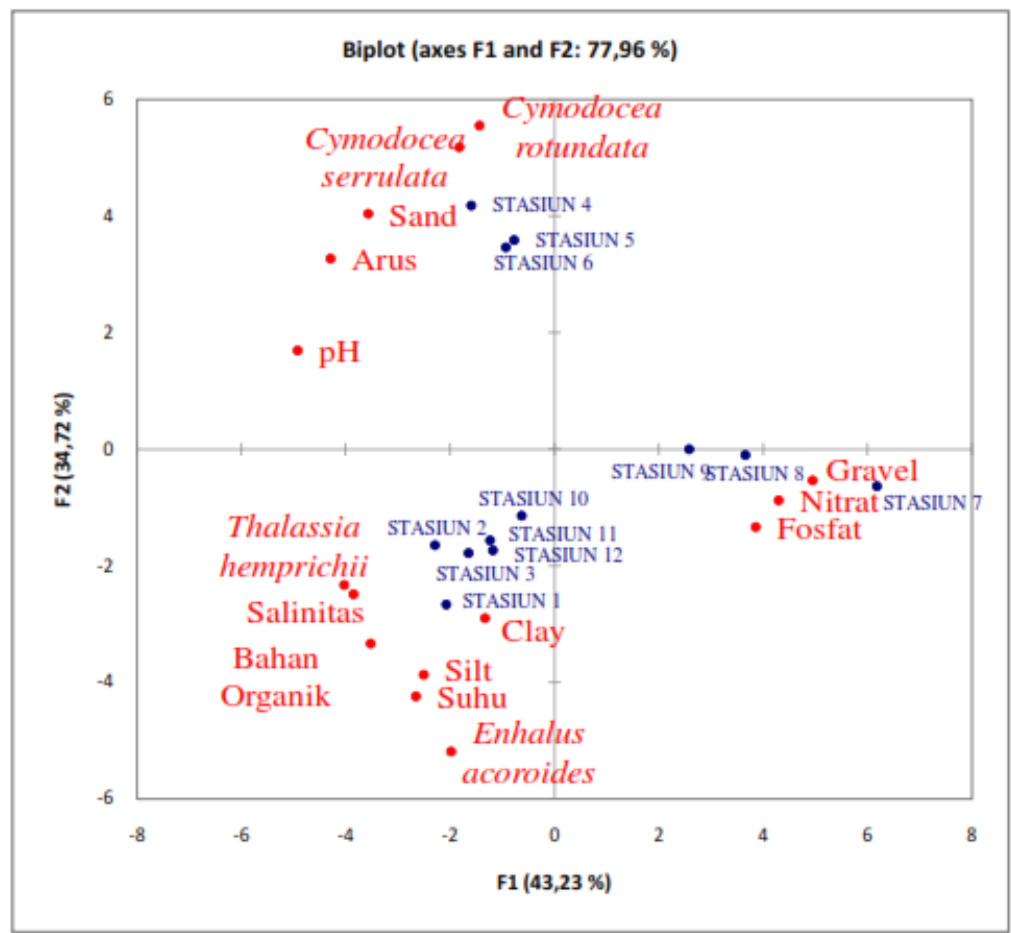

Gambar 1. Analisis PCA pada grafik biplot

\section{KESIMPULAN}

Berdasarkan hasil penelitian analisis Multivariat dengan Principal Component Analysis menjelaskan bahwa Cymodocea serrulata dan Cymodocea rotundata berkorelasi positif dengan sand, arus dan $\mathrm{pH}$. Thalassia hemprichii dan Enhalus acoroides memiliki korelasi positif dengan silt, clay, suhu, salinitas dan bahan organik. Gravel memiliki korelasi postif dengan nitrat dan fosfat.

\section{UCAPAN TERIMAKASIH}

Artikel ini adalah bagian dari Skripsi yang berjudul "Hubungan Jenis Lamun Dengan Jenis Sedimen Di Perairan Pulau Panjang Dan Teluk Awur Jepara" sebagai syarat memperoleh gelar Sarjana Strata Satu Program Studi Ilmu Kelautan Fakultas Perikanan dan IImu Kelautan, Universitas Diponegoro.

\section{DAFTAR PUSTAKA}

Adli, A., Rizal, A. \& Ya'la, Z.R. 2016. Profil Ekosistem Lamun Sebagai Salah Satu Indikator Kesehatan Pesisir Perairan Sabang Tende Kabupaten Tolitoli. Jurnal Sains dan Teknologi Tadulako. 5(1):49-62.

Azkab, M.H. 2006. Ada Apa dengan Lamun. Pusat Penelitian Oseanografi LIPI. Oseana. 31(3):45-55.

Bengkal, K.P., Manembu, S., Sondak, C.F.A., Wagey, B.T., Wagey J.N., Schaduw, J.N.W. \& Lumingas, L.J.L., 2019. Identifikasi Keanekaragaman Lamun Dan Ekhinodermata Dalam Upaya Konservasi. Jurnal Pesisir dan Laut Tropis. 1(1):29-39.

Dahuri, R., Rais Y., Putra S. G., Sitepu, M.J. 2001. Pengelolaan Sumberdaya Wilayah Pesisir Dan Lautan Secara Terpadu. Jakarta: PT. Pradnya Paramita. 305p.

De Silva K.H.W.L. \& Amarasinghe, M.D. 2007. Substrate characteristics and species diversity of marine angiosperms in a micro-tidal basin estuary on west coast of Sri Lanka. Sri Lanka Journal Aquatic Sciences. 12:103 114. 
Feryatun, F., Hendrarto, B. \& Widyorini, N. 2012. Kerapatan dan Distribusi Lamun (Seagrass) Berdasarkan Zona Kegiatan yang Berbeda di Perairan Pulau Pramuka, Kepulauan Seribu. Journal of Management of Aquatic Resources. 1(1):1-7.

Ganefiani, A., Suryanti, S. \& Latifah, N. 2019. Potensi Padang Lamun Sebagai Penyerap Karbon di Perairan Pulau Karimunjawa, Taman Nasional Karimunjawa. Journal of Fisheries Science and Technology. 14(2):115-122.

Handoko, H., Jalil, Z. \& Purnawan, S. 2017. Ukuran Butir Dan Sortasi Sedimen Pada Sungai Gampong Leungah Kabupaten Aceh. Jurnal IImiah Mahasiswa Kelautan dan Perikanan Unsyiah. 2(2):240-245.

Hartati, R., Widianingsih., Santoso, A., Endrawati, H., Zainuri, M., Riniatsih, I., Saputra, W.L. \& Mahendrajaya, R. T. 2017. Variasi Komposisi dan Kerapatan Jenis Lamun di Perairan Ujung Piring, Kabupaten Jepara. Jurnal Kelautan Tropis. 20(2): 96-105.

Hidayat, M., Ruswahyuni. \& Widyorini, N. 2014. Analisis Laju Sedimentasi Di Daerah Padang Lamun Dengan Tingkat Kerapatan Berbeda Di Pulau Panjang, Jepara. Diponegoro Journal of Maquares. 3(3):73-79

Nabilla, S., Hartati, R. \& Nuraini, R A. T. 2019. Hubungan Nutrient Pada Sedimen dan Penutupan Lamun di Perairan Jepara. Jurnal Kelautan Tropis. 22(1):42-48.

Prasetya, D.K., Ruswahyuni., Widyorini, N. 2015. Hubungan Antara Kelimpahan Hewan Makrobenthos Dengan Kerapatan Lamun Yang Berbeda Di Pulau Panjang Dan Teluk Awur Jepara. Diponegoro Journal of Maquares. 4(4):155-163.

Riniatsih, I. 2016. Distribusi Jenis Lamun Dihubungkan dengan Sebaran Nutrien Perairan di Padang Lamun Teluk Awur Jepara. Jurnal Kelautan Tropis. 19(2):101-107.

Rustam, A., Kepel, T.L., Kusumaningtyas, M.A., Ati, R.N.A., Daulat, A. \& Suryono, D.D., Sudirman, N., Rahayu, Y. P. \& Mangindaan, P. 2015. Ekosistem Lamun sebagai Bioindikator Lingkungan di P. Lembeh, Bitung, Sulawesi Utara. Jurnal Biologi Indonesia. 11(2): 233-241.

Rahmawati, S., Irawan, A., Supriyadi, I.H. \& Azkab, M.H. 2014. Panduan Monitoring Padang Lamun. Bogor : PT. Sarana Komunikasi Utama. 21p.

Safwan, M.A., Widada, S. \& Subardjo, P. 2016. Pengaruh Arus Sepanjang Pantai (Longshore Current) Terhadap Sebaran Sedimen Dasar di Perairan Teluk Awur, Jepara. Jurnal Oseanografi. 5(4):415-424.

Saputra, H., Subardjo, P. \& Saputro, S. 2013. Studi Pola Sebaran Sedimen Dasar Akibat Arus Sepanjang Pantai di Sekitar Pemecah Gelombang Pantai Kuta Bali. Jurnal Oseanografi. 2(2):161-170.

Setiawati, T. 2013. Diversitas Genetik Kerabat Liar Ubi Jalar Ipomea trifida (H.B.K) G.DON. Berumbi Asal Citatah Jawa Barat Berdasarkan Karakter Kromosom. Indonesian Journal of Agricultural Science. 3(3): 84-87.

Setyaboma, D. B., Supriharyono. \& Ruswahyuni. 2015. Pengaruh Jarak Pantai Dan Tip Substrat Dasar Perairan Terhadap Kelimpahan Dan Jenis Epifauna Di Perairan Pulau Panjang Sebelah Barat Dan Selatan Jepara. Diponegoro Journal of Maquares. 4(3):20-28.

Umar, H.B., 2009. Principal Component Analysis (PCA) Dan Aplikasinya Dengan SPSS.Jurnal Kesehatan Masyarakat. 3(2):97-101. 